\title{
Expresión corporal, adaptacións curriculares e operacións financeiras: aproveitando sinerxias entre GIDs da UDC
}

\author{
De Llano Paz, Fernando; Carretero García, Míriam²; Martínez Fernández, Paulino; \\ Iglesias Gómez, Guillermo ${ }^{1}$ \\ ${ }^{1}$ Universidade da Coruña, Facultade de Economía e Empresa \\ ${ }^{2}$ Universidade da Coruña, Facultade de Ciencias da Educación \\ GID-UDC en Operacións Financeiras, Economía Enerxética e Economía Circular \\ e GID-UDC en Didáctica da Expresión Corporal e Motricidade (GIEDEM)
}

\section{RESUMO}

A proposta xorde despois dunha reflexión conxunta entre os compoñentes dos dous GIDs da UDC en "Operacións Financeiras, Economía Enerxética e Economía Circular" e "Didáctica da Expresión Corporal e Motricidade (GIEDEM)", sobre a implantación de metodoloxías activas no proceso de ensinanzaaprendizaxe. A idea reside na posta en contacto do alumnado das materias "Expresión corporal e adaptacións curriculares" do Grado en Educación Primaria e de "Análise das Operacións Financeiras" do Grao en Administración e Dirección de Empresas.

A finalidade non é outra que beneficiarse mutuamente do traballo en común das competencias desenvolvidas en cada unha das materias sinaladas. Deste xeito se consegue que 0 alumnado se especialice na súa materia a partir do achegamento aos conceptos e do traballo das competencias a partir da creación de materiais. Cada alumnx se converte en "expertx" que asesora aos da outra materia no tema específico. A avaliación das actividades terá lugar por rúbricas, definidas a partir do deseño conxunto polos membros dos dous GID’s implicados.

PALABRAS CLAVE: Expresión corporal; análise das operacións financeiras; metodoloxías activas; ABP; clase invertida; GIDs. 


\section{CITA RECOMENDADA:}

De Llano Paz, Fernando; Carretero García, Míriam; Martínez Fernández, Paulino; Iglesias Gómez, Guillermo (2020): Expresión corporal, adaptacións curriculares e operacións financeiras: aproveitando sinerxias entre GIDs da UDC. En De la Torre Fernández, E. (ed.) (2020). Contextos universitarios transformadores: Boas prácticas no marco dos GID. IV Xornadas de Innovación Docente. Cufie. Universidade da Coruña. A Coruña (págs. 135-148).

DOI capítulo: https://doi.org/10.17979/spudc.9788497497756.135

DOI libro: https://doi.org/10.17979/spudc. 9788497497756

\section{ABSTRACT}

The proposal arises after a joint reflection between the components of the two Teaching Innovation Groups of the UDC in "Financial Operations, Energy Economics and Circular Economics" and "Didactics of Body Expression and Motor", on the implementation of active methodologies in the teaching-learning process.

The idea is to put the students in contact with the subjects "Corporal expression and curricular adaptations" of the Degree in Primary Education and "Analysis of Financial Operations" of the Degree in Business Administration and Management.

The purpose is none other than to mutually benefit from the common work of the competences developed in each of the indicated subjects. In this way, the students are able to specialize in their subject from the approach to the concepts and the work of the competences from the creation of materials. Each student becomes an "expert" who advises those of the other subject in the specific topic. The evaluation of the activities is by rubrics, defined from the joint design by the members of the two Teaching Innovation Groups involved..

KEY WORDS: Body Expression; Analysis of Financial Operations; Active Methodologies; PBL; Flipped Classroom; Teaching Innovation Groups. 


\section{INTRODUCIÓN}

A iniciativa que se propón xorde despois dun proceso de reflexión conxunta sobre a implantación de metodoloxías activas no proceso de ensinanza-aprendizaxe entre os compoñentes de dous GIDs da UDC: 0 de "Operacións Financeiras, Economía Enerxética e Economía Circular" (adscrito á Facultade de Economía e Empresa) e 0 de "Didáctica da Expresión Corporal e Motricidade (GIEDEM)" (adscrito á Facultade de Ciencias da Educación). Son tres as áreas de coñecemento implicadas: "Didácticas Específicas e Métodos de Investigación e Diagnose en Educación", "Economía Financeira e Contabilidade" e "Economía Aplicada". Como resultado deste proceso de intercambio de experiencias didácticas decidiuse propoñer un novo deseño para o desenvolvemento da materia "Análise das Operacións Financeiras". Con el preténdese dinamizar tanto as horas presenciais como as non presenciais do alumnado.

0 profesorado deste GID en "Operacións Financeiras, Economía Enerxética e Economía Circular" que imparte docencia nesta materia da área de economía financeira e contabilidade ten observado que o nivel de motivación, atención e de asimilación dos conceptos e competencias da materia non son satisfactorios. Deste xeito 0 alumnado aínda que asiste ás clases regularmente, parece non ter un compromiso real co seu proceso de ensinanzaaprendizaxe: os exercicios suxeridos entre sesións de aula polo docente non son realizados. Isto supón que 0 alumnado non completa a parte do proceso que depende da asimilación e traballo dos conceptos presentados e desenvolvidos na aula. É por iso que se propón un cambio no enfoque da materia: motívaselle ao alumnado co reto de ter que formarse como expertxs para poder asesorar ao alumnado doutra materia pertencente a un Grao doutra pola de coñecemento (Figura 1). 
Reflexión conxunta entre GIDs da UDC en "Operacións Financeiras,

Economía Enerxética e Economía Circular" e "Didáctica da Expresión Corporal e Motricidade (GIEDEM)"

O nivel de atención e de asimilación dos conceptos da materia non son satisfactorios

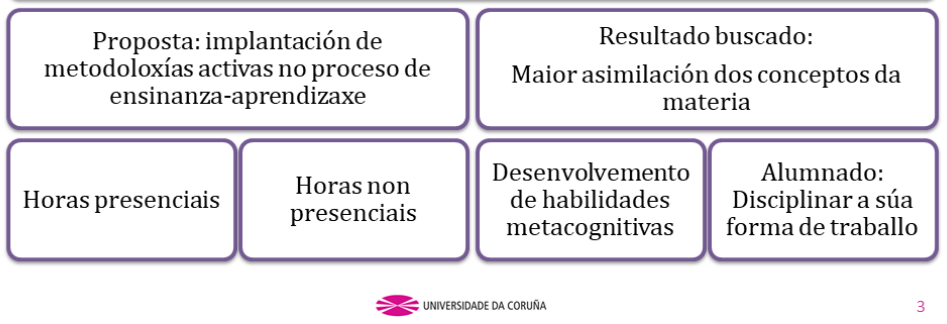

Figura 1. Motivación da proposta

A idea consiste en poñer en contacto no proceso de ensinanza aprendizaxe ao alumnado das materias "Expresión corporal e adaptacións curriculares" optativa de $3^{0}$ curso do Grado en Educación Primaria e ao alumnado de "Análise das Operacións Financeiras" de $1^{0}$ curso do Grao en Administración e Dirección de Empresas. A finalidade non é outra que beneficiarse mutuamente da posta en común das competencias desenvolvidas en cada unha destas materias.

Con isto o novo deseño de "Análise das Operacións Financeiras" basearase no desenvolvemento de tres propostas metodolóxicas ben diferenciadas:

- Achegamento a coñecementos básicos da materia mediante seminarios teóricoprácticos.

- Desenvolvemento dun xogo de rol que inclúe visitas en horas non presenciais a entidades bancarias.

- Realización de tres produtos educativos a desenvolver polo alumnado a través da metodoloxía de aprendizaxe baseada en proxectos (ABP).

0 contacto entre 0 alumnado de ambas materias ten dous momentos relevantes: na preparación do "xogo de rol" cliente -director/a de oficina, no que 0 alumnado da materia da Facultade de Ciencias da Educación transmitiralles a importancia da expresión corporal á hora de comunicar co corpo e os asesorará para preparar ben os roles do xogo; e un segundo 
momento no que 0 alumnado da materia de Finanzas ofrecerá unha breve formación a través dos catro produtos creados ao alumnado de Ciencias da Educación.

A avaliación das actividades terá lugar por rúbricas, definidas a partir do deseño conxunto polos membros dos dous GID’s implicados.

0 resultado buscado é a maior asimilación dos conceptos chave da materia. Isto conseguirase a partir do desenvolvemento das habilidades metacognitivas e dun maior grao de implicación do alumnado a través do traballo encargado para ser realizado na aula e fora da mesma.

0 traballo desenvólvese nos seguintes apartados: No seguinte punto descríbese a base teórica da experiencia, no terceiro punto defínese a proposta metodolóxica e no cuarto apartado achéganse as conclusións principais.

\section{DESCRICIÓN DA EXPERIENCIA. BASE TEÓRICA}

A proposta metodolóxica presenta dúas características que a converten en novidosa: por un lado a explicitación do papel da expresión corporal dentro do proceso ensinanza-aprendizaxe, e por outro, a relación alumnx-alumnx que posibilita 0 éxito da mesma a través da conversión do propio alumnado en axentes formadores do outro grupo de clase do outro grao. Desenvólvense a continuación ambos elementos para contextualizar a experiencia.

\section{1. O PAPEL DA EXPRESIÓN CORPORAL NO PROCESO ENSINANZA-APRENDIZAXE}

Por medio da Expresión Corporal (EC, en diante) e a codificación do corpo en movemento comunicámonos coa entorna, xs outrxs e nós mesmos. Trátase do camiño que nos leva a atopar a nosa propia linguaxe en conexión do físico cos procesos internos indefectiblemente unidos á creatividade (Schinca, 1988).

A través da EC non expresamos, senón que nos comunicamos e nos relacionamos cxs outrxs dende 0 coñecemento propio, adquirindo unha linguaxe persoal dende a corporeidade, 0 movemento e as emocións. Non debemos perder de vista que os coñecementos no ámbito da EC van poder transferirse a todos e cada un dos eidos da vida (Ramos, Cuéllar, y Jiménez, 
2012): xa que, como seres sociais e en constante interrelación, a comunicación cxs outrxs forma parte do noso día a día.

Por todo isto resulta importante implementar, tamén na Educación Superior, ambientes pedagóxicos creativos que permitan ao alumnado construír e desenvolver o seu mundo interior, así como a expresión a través da corporeidade de forma creativa (Learreta, Sierra, \& Ruano, 2005) favorecendo a comunicación entre persoas e abarcando deste modo a EC en todas as súas dimensións, o que permitirá a cada un dxs nosxs alumnxs, tal e como afirma Blanco (2009) "realizarse e proxectarse en si mesmx de forma auténtica e única".

Temos a responsabilidade de favorecer e de potenciar no noso alumnado, non só as súas competencias profesionais senón tamén as persoais, aquelas que lle permitirán desenvolverse e relacionarse ao longo da súa vida. Para isto é preciso que xeremos espazos nas materias máis alá dos contidos teóricos de cada disciplina, espazos para a creatividade e a expresión do propio eu, das emocións, os sentimentos e as ideas que xorden do máis íntimo, espazos onde 0 corpo en movemento sexa unha linguaxe libre e poderosa, que nos permita conectar máis alá das palabras a través do desenvolvemento da EC.

\section{2. A RELACIÓN ALUMNX-ALUMNX}

Cada alumnx é o protagonista do proceso de ensinanza-aprendizaxe no contexto do Espazo Europeo de Educación Superior (EEES). Preténdese que adquira e domine as competencias do Grao coas que poder exercitar a súa capacidade de aprender de xeito continuado. 0 fin último é formar ao alumnado para que sexa quen de xestionar os posibles cambios -laborais e/ou profesionais- que xurdan (Robledo et al. 2015; Riesco 2008).

0 alumnado está chamado a amosar unha maior implicación, compromiso, responsabilidade e autonomía (Figura 2). Con isto facilítanse comportamentos de axuda mutua e diálogo reflexivo: 0 contacto entre iguais debe ser a base do proceso, na que o/a docente toma un papel secundario de asesor da aprendizaxe (Bará e Domingo, 2005; Cano, 2009; Fernández e DeLlano, 2013; Gutierrez e Castro, 2018). 


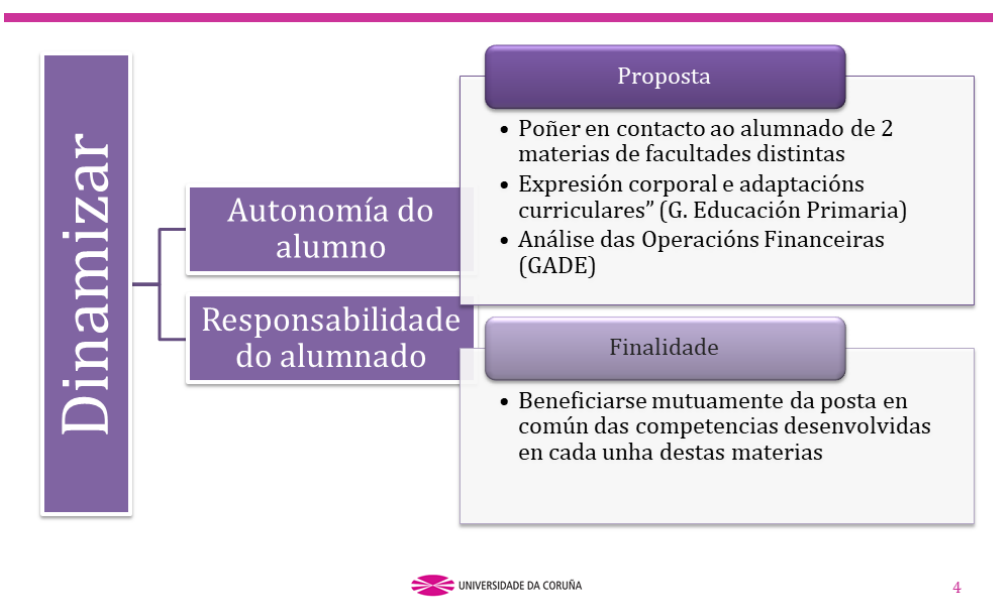

Figura 2. Obxectivos e finalidade da proposta

Deste xeito proponse certa ruptura en canto ao ámbito relacional do alumnado: poñer en contacto a estudantes de dous graos distintos para que interveñan ambos perfís -cada un como experto- no proceso formativo do outro perfil. Este feito contribúe positivamente a motivar o contexto de aprendizaxe do colectivo implicado en cada grao. Por un lado poténciase 0 sentido de pertenza ao grupo, xa que os seus membros van representar, en certa medida, ao colectivo de estudantes da súa facultade. Ao mesmo tempo increméntase no propio grupo o sentido da responsabilidade, xa que serán xs encargadxs de formar aos membros do outro grupo de grao na materia que están a traballar.

No centro da experiencia colocaríase a asimilación dos conceptos e competencias, xa que 0 alumnado ten que ser quen de achegarse á materia na que se teñen que formar e desenvolver as competencias propostas na mesma, e posteriormente ser transmisorxs dos contidos e competencias para formar ao grupo de aula do outro grao. É por iso que a asimilación xoga un papel fundamental, o que contribuirá ao éxito da proposta.

0 traballo de cada grupo de clase levarase a cabo a partir de grupos pequenos. Aínda que en certos momentos se poida traballar en grupo de aula, o funcionamento en pequenos grupos 
facilita unha maior participación -e de calidade- dos individuos e 0 intercambio de ideas e propostas (de Miguel et al., 2005).

\section{DEFINICIÓN DA PROPOSTA METODOLÓXICA}

Xs autorxs deste traballo, que imparten estas materias, entenden que esta proposta metodolóxica é a máis axeitada para desenvolver os seus contidos e competencias. Cada sesión de aula asignada á materia é de 3 horas de duración semanal. Dividiuse e axeitouse 0 contido do programa da materia a 14 sesións, un cuadrimestre. Deste xeito defínese un caso distinto para cada unha das sesións.

0 deseño da materia en cuestión "Análise das Operacións Financeiras" basearase no desenvolvemento de tres propostas metodolóxicas ben diferenciadas que terá lugar ao longo do cuadrimestre.

Iniciarase co achegamento aos coñecementos básicos da materia mediante seminarios teórico-prácticos (Figura 3). 0 tempo previsto é de 4 semanas de clase, as primeiras. Na primeira sesión motivarase ao alumnado e explicaráselle a programación prevista así como a súa temporalización. Neste momento enténdese como fundamental facer unha boa contextualización e motivación da proposta, para conseguir a atención e 0 interese do alumnado por levar a cabo a iniciativa.

As seguintes 3 semanas servirán para preparar 0 xogo de rol. A través deste xogo preténdese facer explícita a relación que hai entre cliente/a e director/a de oficina dunha entidade financeira (Figura 3). Dividirase ao alumnado en 6 pequenos grupos. Deste xeito haberá 3 grupos que prepare cada un a un/ha cliente/a e outros 3 que preparen a un/ha director/a de entidade financeira. Así cada grupo de 4 ou 5 integrantes debe escoller ao seu "actor/actriz" que desenvolverá o seu rol diante ou fronte ao outro/a "actor/actriz" contrario (cliente/a vs. director/a). Cada equipo prepara ao seu "actor/actriz". En cada equipo hai un negociador (actor/actriz) e asesores/as (o resto de membros do grupo). A idea é que o/a cliente/a sexa quen de poñer nervioso/a ao director/a coas súas preguntas ou propostas. Con isto os grupos que 
preparan ao "actor/actriz" cliente/a deben buscar as preguntas a levar a cabo e a información necesaria doutras entidades competidoras (os outros dous grupos) á que representa 0 "actor/actriz" director/a. Estas preguntas están encamiñadas a conseguir un bo financiamento, unha boa oferta por parte da entidade financeira. Doutra banda, os grupos que preparan ao "actor/actriz" director/a deben preparalo/a para poder responder a todas as preguntas que lle vai facer un/ha cliente/a preparado/a. Ao mesmo tempo os dous "actores/actrices" deben levar pensado ou preparado tamén a súa estratexia a seguir, en función da resposta que lle dea a contra-parte. A fin última é tentar chegar a un acordo co que estean contentas as dúas partes negociadoras. Neste momento aproveitarase para visitar algunha entidade financeira cada grupo e poder achegarse ao contexto real dunha oficina deste tipo (Figura 3).

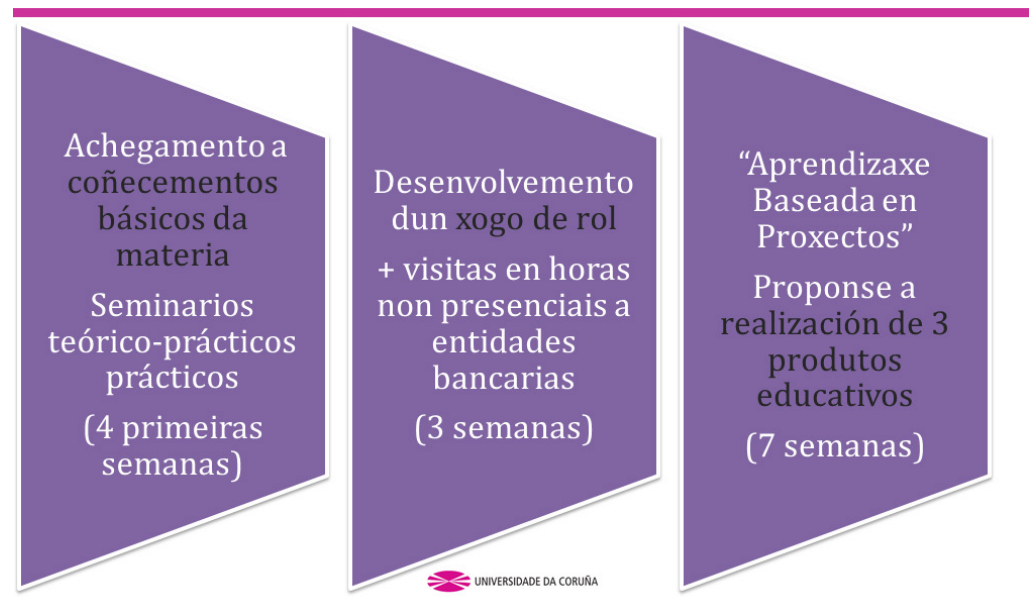

Figura 3. Desenvolvemento da proposta

É no desenvolvemento deste xogo de rol no que ten lugar o asesoramento do alumnado da materia de "Expresión corporal e adaptacións curriculares". 0 alumnado desta materia distribúese entre os 6 grupos de aula formados para asesorar e formar no eido da expresión corporal. 0 alumnado "experto" recomenda aos "actores/actrices" (e ao resto do equipo) que van participar no xogo de rol nos elementos principais a ter en conta á hora de desempeñar os 
dous roles do xogo: director/a ou cliente/a. Con isto se consegue que entre iguais colaboren e xs alumnxs da materia de "Expresión corporal e adaptacións curriculares" se comporten como expertxs que previamente teñen asimilado as competencias e contidos traballados no seu grupo de aula. Finaliza isto coa representación de 3 reunións director/a-cliente/a e a posta en común do desenvolvido neste xogo de rol. Nesta análise posterior $\mathrm{x}$ docente pode aproveitar para concretar e traballar algúns conceptos que puideran non ter quedado claros.

Durante as seguintes 7 semanas levarase a cabo a metodoloxía de "Aprendizaxe Baseada en Proxectos (ABP)" coa que propoñer a realización de tres produtos educativos a desenvolver polo alumnado: creación dun vídeo explicativo dos conceptos básicos da materia (clase invertida) incluíndo o xogo de rol; realización de "minutos-tweets financeiros" para ser difundidos pola radio e a gravación de podcasts con exemplos prácticos de operacións financeiras (Figura 4).

Unha vez creados os produtos, estes servirán para formar ao grupo de clase da materia "Expresión corporal e adaptacións curriculares" por parte do alumnado de "Análise das Operacións Financeiras". Deste xeito o alumnado de finanzas, unha vez asimiladas as competencias e os contidos, forman nos conceptos básicos en operacións financeiras ao alumnado do grao en Educación -entre iguais-.

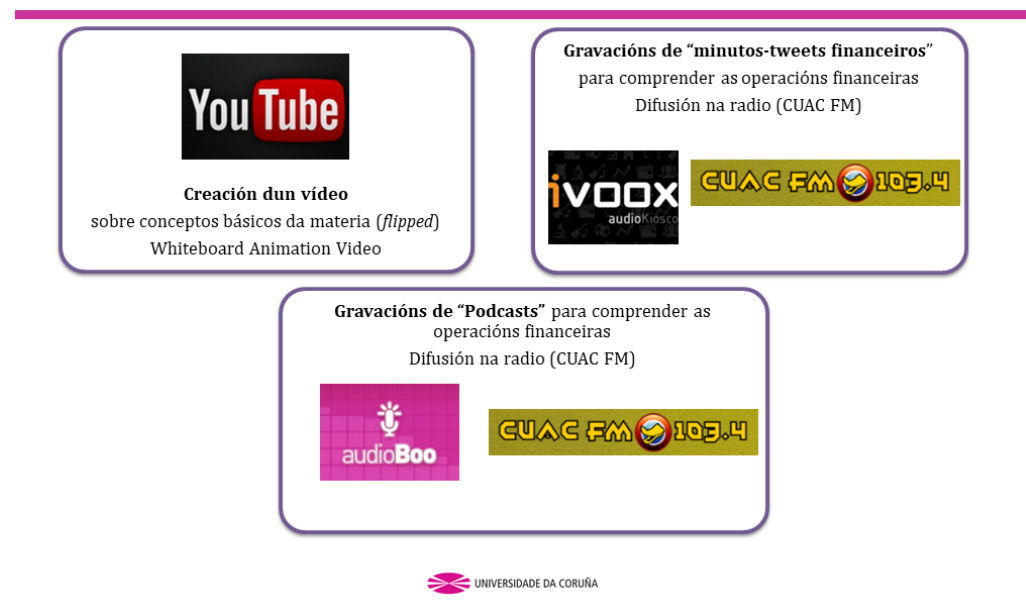

Figura 4. Produtos educativos resultantes 
A motivación de creación destes produtos radica, tanto en favorecer a asimilación dos conceptos como na posibilidade de ser compartidos con outros grupos ou destinatarios como poden ser alumnas e alumnos de Educación Secundaria, ONGs, a Cruz Vermella, etc.

\section{CONCLUSIÓNS}

Da reflexión conxunta -sobre a necesidade da implantación de metodoloxías activas no proceso de ensinanza-aprendizaxe- entre os membros dos dous GIDs da UDC de "Operacións Financeiras, Economía Enerxética e Economía Circular" (adscrito á Facultade de Economía e Empresa) e 0 de "Didáctica da Expresión Corporal e Motricidade (GIEDEM)" (adscrito á Facultade de Ciencias da Educación) xorde esta iniciativa.

Esta proposta novidosa de xuntar ao alumnado de dúas titulacións contribúe positivamente a desenvolver e acadar os obxectivos do proceso de ensinanza-aprendizaxe das materias en cuestión. A finalidade non é outra que beneficiarse mutuamente do traballo en común das competencias desenvolvidas en cada unha das materias sinaladas. 0 feito de que 0 propio alumnado asuma o papel protagonista de transmisor e formador nas competencias e contidos inicialmente traballados na materia da titulación de referencia potencia a súa asimilación. Así mesmo que os receptores desta formación sexa outro grupo de iguais dunha clase doutra titulación incrementa 0 sentido de pertenza ao grupo de clase propio, o que conduce a unha maior motivación cara o reto proposto, e potencia e enriquece o proceso de ensinanza-aprendizaxe.

Co deseño desta experiencia búscase dar resposta a unha certa ausencia de motivación ou desinterese amosado polo alumnado da Facultade de Economía e Empresa na materia. En certa medida, é posible, que 0 alumnado que cursa estes estudos presente inicialmente un perfil vocacional non tan claro ou directo como o pode presentar alumnado da Facultade de Ciencias da Educación. É por iso que mediante esta proposta educativa, que inclúe cambios metodolóxicos e de creación de contidos e produtos formativos, se pretende crear o contexto positivo para favorecer 0 achegamento, 0 desenvolvemento e a asimilación dos conceptos e competencias da materia por parte deste alumnado en parte desconectado do seu proceso de ensinanza-aprendizaxe. 


\section{REFERENCIAS}

Bará, M. \& Domingo, J. (2005). "Técnicas de aprendizaje cooperativo. Taller de Formación. Universitat Politécnica de Catalunya". Recuperado de:

http://www.catedu.es/doc_intercultural/recursos/pdfs/TecnicasAprendizajecooperativo.pdf.

Blanco, M. J. (2009). Enfoques teóricos sobre la expresión corporal como medio de formación y comunicación. Horizonte Pedagógico (11) 1, 15-28.

Cano, R. (2009). Tutoría universitaria y aprendizaje por competencias ¿Cómo lograrlo?. Revista Electrónica Interuniversitaria de Formación del Profesorado, 12 (1), pp. 181 204. Recuperado de: http://www.aufop.com/

De Miguel, M. (Dir); Alfaro, I.J., Apodaca, P., Arias, J.M.; García, E.; Lobato, C. \& Pérez, A. (2005). Modalidades de enseñanza centradas en el desarrollo de competencias. Orientaciones para promover el cambio metodológico en el Espacio Europeo de Educación Superior. Oviedo (España): Universidad de Oviedo.

Fernández, M. \& De-Llano, F. (2013). El Plan de Acción Tutorial en la Universidad: Seguimiento del PAT de la Facultad de Economía y Empresa de la UDC y su función como plataforma educativa integral dentro del EEES. Taller Docente de la XV Reunión de Economía Mundial (REM). La riqueza cambiante en la Economía Mundial, Santander. Recuperado de: https://dialnet.unirioja.es/servlet/articulo?codigo $=4268883$.

Gutierrez, P. \& Castro, M.P. (2018). El aprendizaje entre iguales como metodología de trabajo para la inclusión educativa. Experiencia docente en una escuela de Extremadura. Revista de Investigación en Educación, 1 (16), pp. 78-92.

Learreta, B., Sierra, M. A., y Ruano, K. (2005). Los contenidos de Expresión Corporal. Barcelona: INDE.

Ramos, J., Cuéllar, M. J., y Jiménez, F. (2012). Nuevos retos en el desarrollo curricular de la Expresión Corporal. EmásF, Revista Digital de Educación Física (14), 142-149.

Riesco, M. (2008). El enfoque por competencias en el EEES y sus implicaciones en la enseñanza y el aprendizaje. Tendencias Pedagógicas, 13, pp. 79-105. 
Robledo, P., Fidalgo, R., Arias, O., Álvarez, M.L. (2015). Percepción de los estudiantes sobre el desarrollo de competencias a través de diferentes metodologías activas. Revista de Investigación Educativa, 33(2), 369-383.

Schinca, M. (1988). Expresión Corporal. Madrid: Escuela Española. 
